\title{
RIGID VALGUS FOOT FROM FIBROUS CONTRACTURE OF THE PERONEI
}

\author{
A. J. Harrold, London, England \\ From St Mary's Hospital, London
}

In a review of the etiology of peroneal spastic flat foot, Harris and Beath in 1948 showed that this term was often applied indiscriminately and inaccurately to rigid flat feet of at least three different types. In two there was an anomaly of tarsal structure with fusion of the calcaneum either to the navicular bone or to the talus. A deformed, rigid foot was produced without true peroneal spasm, although those muscles were adaptively shortened because of the valgus deformity. The third type was caused by an inflammatory arthritis of the tarsal joints with protective peroneal spasm which twisted the foot into valgus. In their own series of seventeen cases twelve had a talo-calcaneal bridge, three had calcaneo-navicular bars and

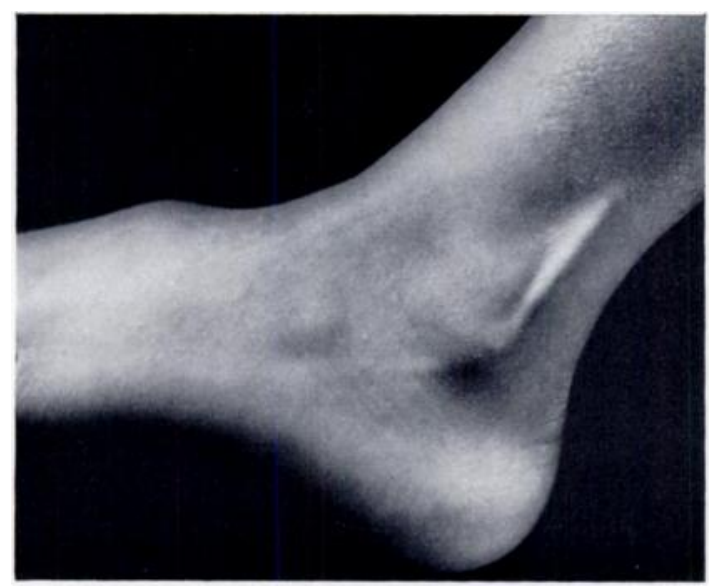

Fig. 1

Prominence of the peroneal tendons on attempting to invert the foot.

two had tarsal rheumatoid arthritis. In a later paper Harris (1955) showed how a talo-calcaneal bar could be present even with seemingly normal radiographs. Waugh (1957) has since described a partial cubo-navicular coalition associated with peroneal spasm and deformity.

A child with an organic contracture of the peroneal muscles causing a rigid flat foot is reported here.

Case report-A girl aged six complained of a long-standing deformity of the left foot with recent occasional aching. The deformity, first noticed at the age of two and a half, had been treated by manipulation and plaster, exercises, insoles, injection of the subtalar joint and special boots all without avail. Clinical examination showed that the left foot was held in full eversion. and inversion, when attempted, was impossible, but threw the peroneal tendons into prominence laterally (Fig. 1). There was no sign of arthritis elsewhere. Radiographs of the feet taken at three and six years old showed no tarsal anomaly.

At operation the peroneal contracture persisted, despite the anaesthesia. The tendons, exposed with the object of lengthening them, were noticed to have no muscle fibres attached to them. On extending the incision upwards the peroneus brevis was found to consist of some pale muscle fibres but no muscle tissue could be seen attached to the peroneus longus tendon. After biopsy the tendons were lengthened and full passive inversion of the foot was restored. 
Histological study showed that the specimen from the peroneus longus muscle consisted almost entirely of mature collagen in which were enclosed scanty muscle fibres (Fig. 2); most of the latter were about normal in size with normal striations although some were atrophic. The specimen from the peroneus brevis muscle (Fig. 3) showed that three-quarters of the muscle was replaced by fat, with a very little collagen. The muscle fibres were mostly in small groups, but a few were isolated; also they were mostly of normal size and striation, and they had normal sarcolemmal nuclei.

Further examination of the child's early history showed that, at the age of eighteen months, she had been in hospital for three weeks, severely ill with pyelitis and septicaemia. Treatment had included intravenous fluids for which the left leg had been used. A splint had been applied

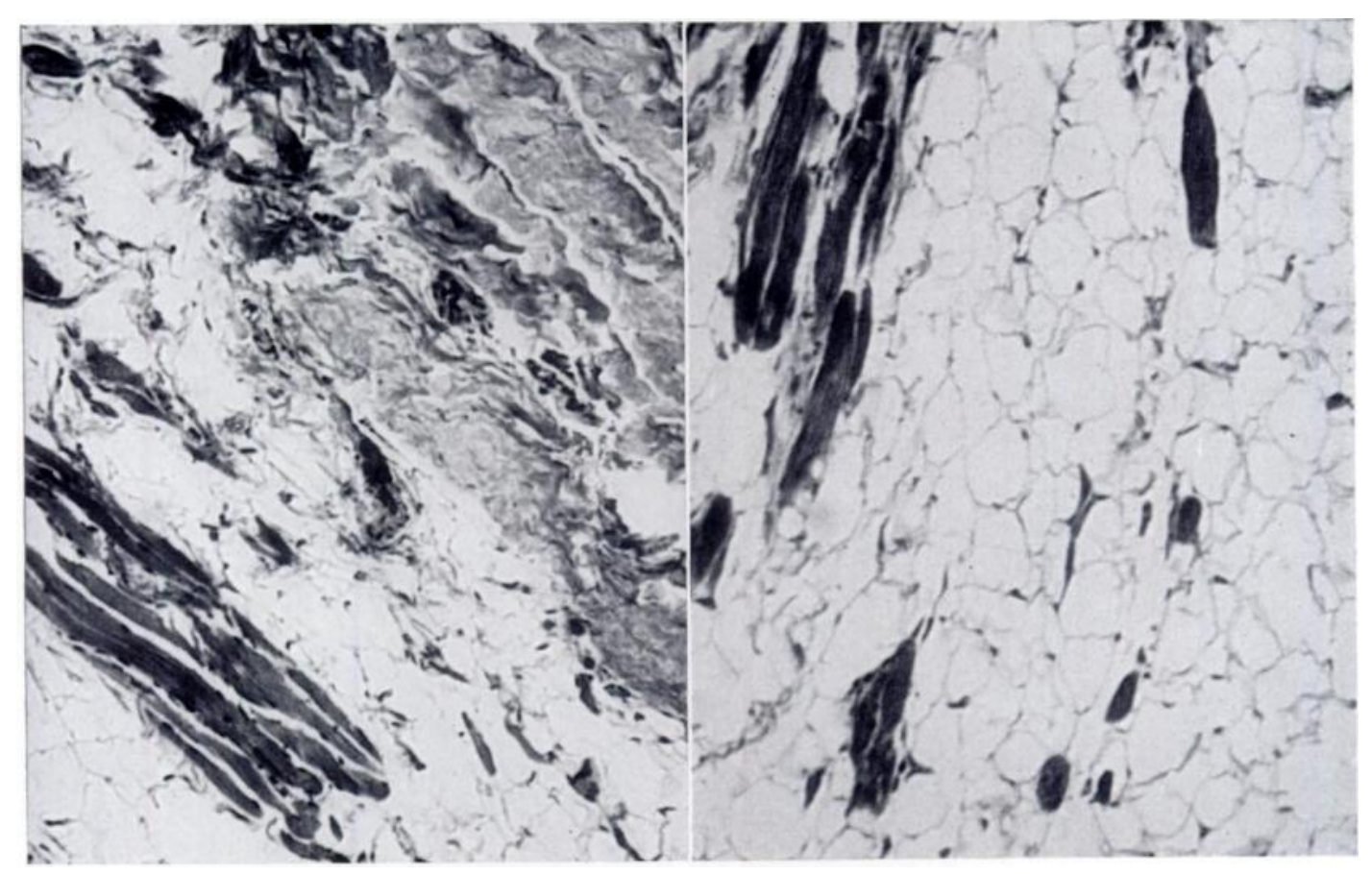

Fig. 2

Fig. 3

Figure 2-Specimen from peroneus longus. The muscle is almost entirely replaced by fat and collagen. (Haematoxylin and eosin, $\times 100$.) Figure 3-Specimen from peroneus brevis. Small groups of muscle fibres are widely separated by fat. (Haematoxylin and eosin, $\therefore 100$.)

and the notes record that at the time of leaving hospital the baby had the remains of a pressure sore on the left calf. This healed in two months, to leave at the age of six a barely visible, slightly dimpled scar over the outer aspect of the leg a short distance below the knee.

\section{DISCUSSION}

There are several possible explanations for the fibrous contracture of the peroneal muscles in this patient. Pressure from the splint on the leg of an almost moribund infant, perhaps combined with local sepsis in the pressure sore, might have led to muscle death in the peroneal compartment. It may be recalled that, in young adults, exertion alone may cause ischaemic necrosis of the peronei and that contracture has sometimes followed (Blandy and Fuller 1957).

Recent papers by Gunn (1964) and Lloyd-Roberts and Thomas (1964) have shown an association between muscle contracture and intramuscular injections and transfusions in infancy, although in their patients only the quadriceps femoris has been involved. In this child there was a clear history of an intravenous transfusion into the affected leg although the 
precise site of the injection was not discovered. It could well be that the contracture of the peroneal muscles arose like the quadriceps contracture, from oedema and inflammation within the muscle sheath caused by leakage from, and irritation by, the intravenous transfusion.

In the child reported here the contracture presented as though it was yet another variety of so-called peroneal spastic flat foot.

\section{SUMMARY}

1. A child with a rigid valgus foot caused by fibrous contracture of the peronei muscles is described.

2. The probable cause of the contracture is discussed.

I am indebted to Dr Stephanie Wilson for the histological report and for the photomicrographs.

\section{REFERENCES}

Blandy, J. P., and Fuller, R. (1957): March Gangrene. Journal of Bone and Joint Surgery, 39-B, 679.

GunN, D. R. (1964): Contracture of the Quadriceps Muscle. Journal of Bone and Joint Surgery, 46-B, 492.

Harris, R. I. (1955): Rigid Valgus Foot due to Talocalcaneal Bridge. Journal of Bone and Joint Surgery, 37-A, 169.

Harris, R. I., and Beath, T. (1948): Etiology of Peroneal Spastic Flat Foot. Journal of Bone and Joint Surgery, 30-B, 624.

Lloyd-Roberts, G. C., and Thomas, T. G. (1964): The Etiology of Quadriceps Contracture in Children. Journal of Bone and Joint Surgery, 46-B, 498.

Waugh, W. (1957): Partial Cubo-Navicular Coalition as a Cause of Peroneal Spastic Flat Foot. Journal of Bone and Joint Surgery, 39-B, 520. 